This is a post-peer-review, pre-copyedit version of an article published in Synthese. The final authenticated version is available online at:

http://dx.doi.org/10.1007/s11229-018-1851-3

\title{
Phenomenology and Naturalism in Autopoietic and Radical Enactivism: Exploring Sense-Making and Continuity from the Top Down
}

June 2018

Hayden Kee

Fordham University

\section{Acknowledgments}

I would like to express my gratitude to Jennifer Gosetti-Ferencei, Shaun Gallagher, John Drummond, Maxime Doyon, Katsunori Miyahara, Robert Duffy, Samuel Kampa and Simon Rousseau-Lesage for comments on earlier versions of this paper. Helpful feedback was also provided by participants at the conference The World in Us: Gestalt Structure, Phenomenology and Embodied Cognition (7-9 July 2017, University of Edinburgh) and participants in Maxime Doyon's seminar on enactivism at University of Montreal (Fall 2017). The paper benefited immensely from the thorough and insightful commentary provided by two anonymous reviewers for Synthese.

\section{Keywords}

Enactivism, phenomenology, naturalism, naturalized phenomenology, sense-making, autopoiesis, lifemind continuity thesis, Maurice Merleau-Ponty, Hans Jonas, Wolfgang Köhler

\section{Abstract}

Radical and autopoietic enactivists disagree concerning how to understand the concept of sense-making in enactivist discourse and the extent of its distribution within the organic domain. I situate this debate within a broader conflict of commitments to naturalism on the part of radical enactivists, and to phenomenology on the part of autopoietic enactivists. I argue that autopoietic enactivists are in part responsible for the obscurity of the notion of sense-making by attributing it univocally to sentient and non-sentient beings and following Hans Jonas in maintaining a phenomenological dimension to life-mind continuity among all living beings, sentient or non-sentient. I propose following Merleau-Ponty instead, who offers a properly phenomenological notion of sense-making for which sentience is a necessary condition. Against radicalist efforts to replace sense-making with a deflationary, naturalist conception of intentionality, I discuss the role of the phenomenological notion of sense-making for understanding animal behavior and experience. 


\section{Introduction}

In recent literature on enactivism, several of the movement's core concepts and theoretical commitments have been put on trial. Autopoietic enactivism (AE), now cast by some as the old guard, is committed to a notion of sense-making, informed by both phenomenology and autopoietic theoretical biology, that is ascribed liberally throughout the organic world (Thompson 2007, 2011; Thompson and Stapleton 2009). In producing and maintaining itself in existence as a living thing individuated against its environment, an organism at the same time selectively delineates a domain of possible meaningful engagements with that environment. It enacts (brings forth, or makes sense of) its environment from its unique perspective. In identifying sense-making as a fundamental trait of all living organisms, AE at the same time establishes a deep continuity between life and mind, a phenomenologically informed sense of subjectivity that can be ascribed univocally to all living things from bacteria to human beings.

Radically enactive approaches to cognition (REC), inspired in part by $A E$ and other dynamic and $4 E$ approaches in the cognitive sciences, seeks to radicalize the enactivist project by setting it upon a rigorously naturalist conceptual foundation consistent with the empirical sciences (Hutto and Myin $2013,2017)$. It accuses classical approaches in the cognitive sciences of being committed to a notion of content, or conditions of satisfaction, that is inconsistent with a thoroughgoing naturalism. To ensure that similar allegations cannot be raised against enactivism, REC proposes to "RECtify" AE's notion of sense-making, which REC advocates fear may contain lingering traces of "content." Extending this line of critique, $A E$ 's phenomenological heritage has been called into question and concerns have been raised about its suitability as a rigorously naturalist foundation for an embodied cognitive science (De Jesus 2016a).

My first objective in this paper is to clarify the stakes of the debate between REC and AE. Far from being merely terminological, I argue that there are substantive theoretical differences between phenomenologically-inspired AE and naturalist REC. I defend enactivism's phenomenological heritage, arguing that the radicalist critique largely misses its mark. A distinctively phenomenological notion of sense-making has vital work to do within enactivist discourse that cannot be achieved by REC's deflationary notion of intentionality. That said, I also grant that some AE authors are in part responsible for confusing the phenomenological dimension of enactivism by following Jonas in using phenomenological concepts to describe the "experience" of non-sentient organisms. Against this Jonasian turn, I propose taking up the Merleau-Pontian branch of enactivism's phenomenological lineage, which, I argue, reserves properly phenomenological descriptions for sentient creatures alone. I conclude by proposing an approach to sense-making and life-mind continuity that explores the phenomenological dimension of continuity from the top down, rather than the bottom up, beginning with the experience and behavior of those organisms that are closest to us in the phylogenetic tree rather than furthest away. This allows us to clarify the phenomenological notion of sense-making and demonstrate the indispensable work it does in enactivist theory.

\section{Phenomenology and Autopoiesis in Autopoietic Enactivism}

In order to understand the concept of sense-making developed in $\mathrm{AE}$, we must situate the movement at the nexus of the various influences that have shaped it. One of the foundational ambitions of $A E$, as stated in Varela, Thompson, and Rosch's 1991 breakthrough work The Embodied Mind, was to enlarge the horizon of the sciences of mind to include lived human experience (Varela et al. 1991/2016, Ixi). This 
effort was cast as a revitalization and continuation of Merleau-Ponty's project of providing a unified account of, on the one hand, our lived experience of being a living thing, and, on the other, our scientific knowledge of what a living thing is. A central aspect of this project was to provide an account of the most basic mode of cognition in nature described from both first-personal and third-personal perspectives. The phenomenological tradition, rehabilitated into the fold of this emerging embodied cognitive science, provided the first-person account, while the autopoietic theory of life, developed by Varela and Maturana in the preceding decades (Maturana and Varela 1980), provided the third-person, theoretical-biological underpinning.

The Embodied Mind presented the first steps towards such a convergence of autopoietic biological theory and phenomenology. The proposed convergence was illustrated using the model of a digital cellular automaton, Bittorio. An autonomous system structurally coupled to its environment, Bittorio shows emergent dynamic patterns of covariant response to its surroundings when immersed in a "milieu" of surrounding 1s and 0s (Varela et al. 1991/2016, 150ff.). This model was interpreted by Varela et al. as showing how an autonomous system "enacts," "selects," or "brings forth a domain of significance out of the background of its random milieu" (156). Though the authors admit that such "interpretation" is "a far cry from the kinds of interpretation that depend on experience," they maintain that it is interpretation nonetheless, a minimal form of the same kind of interpretation that interests phenomenological and hermeneutic authors such as Heidegger and Gadamer. The cellular automaton, and the unicellular organism that it models, can thus be said to enact or bring forth a world in a sense continuous with that in which a human agent does.

These first efforts on AE's part to establish the continuity of life and mind in both biological and phenomenological terms were admittedly cursory, and will have left many more classically-minded phenomenologists unconvinced. There seem to be too many essential characteristics of any phenomenologically robust account of interpretation missing from the case of basic cognition (e.g., sentience, temporality, and flexibility in perception and behavioral response) to warrant a univocal ascription of "interpretation" to Bittorio and a human subject. A decisive moment in AE's efforts to fashion a more plausible bridge between theoretical biology and phenomenology came in the early 2000s when several prominent AE authors turned to the work of the phenomenologist Hans Jonas (Weber and Varela 2002; Di Paolo 2005; Thompson 2007). A student of Heidegger, Jonas was immersed in both the phenomenology and the theoretical biology of his time and already approached much the same problematic as contemporary AE authors in his own efforts to establish the continuity of life and mind.

Jonas promised to mend the gap left open in The Embodied Mind's effort to link up a phenomenological approach to experience with the autopoietic theory of life. Jonas' unifying role in AE thought is most clearly articulated in Evan Thompson's Mind in Life. ${ }^{1}$ While a thorough exposition is beyond the scope of the present paper, I will here offer a brief sketch of these three central components of AE's life-mind continuity thesis as elaborated in Mind in Life: (1) The autopoietic approach to life as cognition, (2) the Merleau-Pontian phenomenology of animal behavior, and (3) the Jonasian argument for extending the phenomenological dimension of life-mind continuity all the way down to the most basic living systems.

\footnotetext{
${ }^{1}$ Thompson (2007), chapters 4-6. Henceforth cited as MiL.
} 
From the autopoietic theory of life, AE draws its account of what it is to be a living thing, and a basic biological notion of cognition that applies univocally to all living things. According to Varela's simplified definition of autopoiesis (Varela 2000), for a system to be autopoietic,

(i) the system must have a semipermeable boundary; (ii) the boundary must be produced by a network of reactions that takes place within the boundary; and (iii) the network of reactions must include reactions that regenerate the components of the system. (MiL, 101)

The most basic case, and the clearest illustration, of autopoiesis in the organic realm is the unicellular organism. It has (i) a semipermeable boundary, the cell membrane that individuates it from its environment while still allowing an exchange of materials with that environment. The cell membrane is (ii) produced by basic metabolic processes occurring within the cell, and (iii) these same processes maintain the system itself, including the cell membrane, by regenerating the components of the system.

All organisms are autopoietic systems in the sense just elaborated. Further, all living systems are also cognitive systems, in the sense determined within the framework of autopoietic theory. At the same time as the living system establishes a boundary and thus individuates itself vis-à-vis its environment, it also delineates a realm of possible engagements with that environment based on its particular organization and the material requirements of its autopoietic processes. Maturana clearly articulates this aspect of the autopoietic theory of cognition:

A cognitive system is a system whose organization defines a domain of interactions in which it can act with relevance to the maintenance of itself, and the process of cognition is the actual (inductive) acting or behaving in this domain. Living systems are cognitive systems, and living as a process is a process of cognition. This statement is valid for all organisms, with and without a nervous system. (Maturana 1980, qtd. in MiL, 124 - emphasis added)

Autopoietic theory thus delivers to AE a univocal sense of "cognition" that can be ascribed to all living organisms, establishing the continuity of life and mind (cognition) scientifically from the third-person perspective and from the bottom up, as it were, taking as its exemplar the simplest autopoietic living being.

However, in order to realize its ambition of linking up the experiential dimension of mind with cognitive science, the continuity thesis must also be established top-down, phenomenologically from the firstperson perspective. Here, Merleau-Ponty's The Structure of Behavior (Merleau-Ponty 1963) provides a phenomenological account of behavior as the nexus of consciousness and nature (3). Merleau-Ponty argues that reductionist accounts of behavior (such as those offered by classical behaviorism) that attempt to explain behavior as an external relation of organismic response to stimuli fail to account for the openness and flexibility of animal behavior. We must think of behavior not as an external relation of stimulus and response, but rather as an internal, structural relation between an organism and its environment. The relation is structural and internal because the parts, or moments, only are what they are with reference to the whole. This is true not only of isolated actions, which only have their meaning insofar as they are situated within the ongoing temporal continuity of the organism's life. It also holds for the organism-environment coupling itself. The environment is an environment-for-the-organism: its 
significance and general perceptual articulation depend on the interests, history, and sensorimotor possibilities of the organism in question. ${ }^{2}$

Merleau-Ponty's structural and phenomenological account of behavior brings us some ways towards linking up the autopoietic concept of cognition with a phenomenological account of subjectivity. Nonetheless, a gap still looms. For Merleau-Ponty's concern in The Structure of Behavior is with consciousness, understood now as sensorimotor animal behavior, the intertwining of mind and body in sentient organisms embedded in their lifeworlds. His numerous examples draw from insect, arachnid, fish, reptile, amphibian, bird, and mammal behavior. But at no point does he discuss examples from outside of the animal kingdom. Indeed, within the animal kingdom, he discusses only creatures with central nervous systems. Admittedly, Merleau-Ponty explicitly states neither how broadly distributed behavior is within the organic world, nor what its minimal exemplar is. His notion of behavior does, however, appear to be consciousness-involving, in the novel sense of consciousness that he develops (Merleau-Ponty 1963, 3-5, 43, 75f., 92, 164). And there is no reason to assume that such behavior is evident in creatures without a nervous system. Prima facie, then, it is by no means clear that the Merleau-Pontian, phenomenological notion of animal behavior is coextensive with an autopoietic conception of cognition that is meant to apply to all organisms.

It is here that Jonas' phenomenological biology promises to bridge the gap, transposing the phenomenological level of description all the way down to the unicellular organism. Where MerleauPonty employs the notion of behavior to extend the domain of phenomenological description to (at least some) non-human animals, Jonas takes metabolism to be a basic biological notion in need of phenomenological interpretation. Wherever the basic chemical processes of self-preservation can be found, we find also the same existential conditions that shape human life, and hence the categories of existential phenomenology crafted to describe human existence apply also at the level of unicellular existence. Subjectivity, freedom, meaning, autonomy, dependence, creativity, mortality - in a minimal degree, these categories apply to the humble bacterium just as they do to the human being. For "the great contradictions which man discovers in himself [...] have their rudimentary traces in even the most primitive forms of life" (Jonas 1966, ix; cf. MiL, 129). Jonas thus emerges as the lynchpin figure in AE's continuity thesis, establishing from the top down the continuity of life and mind that autopoietic theory establishes from the bottom up. The gap now bridged, the autopoietic concept of cognition and the Merleau-Pontian concept of behavior can be seen as identifying one and the same phenomenon from the perspective of different theoretical interests. ${ }^{3}$

It is important not to misstate the enactivist view concerning life-mind continuity, phenomenological description, and sentience. Colombetti provides a helpful interpretation of the sense in which, for the Jonasian inspired continuity thesis, life prefigures mind:

Mind shares the organizational properties of life, and richer forms of mind depend on richer forms of life. [...] But this means [...] not that consciousness, not even in some minimal nonreflective form, is present in all forms of life. Rather, the idea here is that the autonomous and adaptive

\footnotetext{
${ }^{2}$ Cf. MiL 66ff. Sheredos (2017) provides a helpful clarification of Merleau-Ponty's notion of structure, and a critique of Thompson's appropriation of Merleau-Ponty in MiL.

${ }^{3}$ In fact, Thompson equates the two already at MiL 126, before introducing Jonas. But it is clear that Jonas' line of reasoning is meant to ensure the coextension of the biological and phenomenological dimensions of the life-mind continuity thesis.
} 
organization of living systems sets up an asymmetry between them and the rest of the world, such that living systems realize a perspective or point of view from which the world acquires meaning for them, and not vice versa. (Colombetti 2014, 19f.)

However, even with this qualification in place, I believe the equation of Merleau-Ponty's phenomenological notion of behavior with the autopoietic concept of basic organismic "cognition" to be mistaken. I will argue below that the Jonasian turn has introduced a fateful equivocation into AE that has incited suspicion towards its phenomenological heritage. But first, let us consider the critique of the $A E$ account of cognition that has emerged from the corner of REC, and the ensuing critique of $A E$ 's phenomenological heritage.

\section{The Radical Critique}

In recent years, Radically Enactive Cognition (REC), especially as represented in the work of Daniel Hutto and Erik Myin ${ }^{4}$, has emerged as an alternative variant within the enactivist landscape. As varieties of enactivism, REC and AE have much in common: both seek to break decisively with cognitivism and representationalism, and the associated "information-processing" model of cognition once dominant in cognitive science; both seek to overturn the classical dualisms that have characterized much of philosophy of mind and cognitive science; both emphasize the importance of active, embodied, environmentally-situated engagements for our understanding of organisms and their mentality; and both view understanding developmental processes as necessary to the understanding of life and mind.

REC and AE part ways, however, over AE's more "extravagant claims" (RE 5) - claims that concern the phenomenological aspects of $A E$ and its liberal view on the extent of cognition in the organic domain. To understand REC's complaint here, we must understand the movement's broader ambition of establishing a firm theoretical foundation for enactivism consistent with explanatory naturalism. Hutto and Myin's master argument consists in confronting alternative views in the cognitive sciences with the "hard problem of content" (RE 57ff., EE 41ff.). Approaches in the cognitive sciences that invoke the notion of content (i.e., conditions of satisfaction, broadly construed) to understand the most basic activities of mind are accused of being committed to an understanding of the mind that is inconsistent with explanatory naturalism. The only "scientifically respectable" (RE XV) concept of information that one can ascribe at the level of basic mentality is covariance, the regular co-occurrence of two states of affairs such that one can be said to carry information about the other. And since content involves notions of truth, representation, and implication, notions which cannot be cashed out in terms of covariance, invoking content at the level of basic minds runs afoul of explanatory naturalism.

Hutto and Myin claim that vestiges of cognitivism linger where AE authors assert that organisms "create and carry meaning" through their embodied activity, or that adaptive responding at the level of basic cellular activity entails a kind of "sense-making" in which organisms "enact" or "bring forth" their environments (RE 32ff., EE 75ff.). REC goes beyond AE in rejecting "all remnants of the idea that organismic responses relevant to basic mentality are responses that create, carry, and consume meanings" (RE 34). They object that the meaning of such parlance has not been rendered sufficiently

\footnotetext{
${ }^{4}$ Hutto and Myin (2013, 2017). Henceforth cited as RE and EE respectively.
} 
clear by AE authors (see also De Jesus 2016a). As such it is at best misleading or confused, and at worst evidence of a lingering representationalist contamination within the $A E$ framework.

In place of AE's strong continuity of life and mind, REC posits a stark duality of basic and scaffolded minds. Basic cognition involves intentional directedness (though not necessarily phenomenality) without entailing content in the sense of specified conditions of satisfaction (RE $x$ ). Scaffolded minds, which are capable of sense-making and operating with specified conditions of satisfaction, can be built upon basic minds, but only with the help of enculturation and the external scaffolding of linguistic symbols that it provides (EE 121ff.; Hutto and Satne 2015). The details of the emergence of content-involving minds from the basis of contentless, basic mentality need not concern us here, though we should note in passing the stark dichotomy between the two modes of cognition, and the vast array of cognitive, behavioral, and experiential phenomena that are thus lumped together under the heading of "basic mentality." This latter notion is supposed to be elaborated strictly in terms of covariation, and has a tremendous amount of explanatory lifting to do for such a deflationary concept.

Hutto and Myin's concerns about AE's liberal notion of cognition have recently been taken up by De Jesus (2016a), who identifies these problematic aspects of the AE project as arising specifically from its phenomenological heritage. Once the phenomenological dimension of AE has become suspect, De Jesus locates a number of further issues there. These include (1) conflating ontological and epistemological principles; (2) a reliance on analogy, inference, or projection as the only mode of access to other minds, human or non-human; and (3) anthropomorphic leanings in the interpretation of non-human cognition. De Jesus urges that enactivists should thus part with the phenomenological heritage that undermines the movement's theoretical stability and explore alternative frameworks for elaborating a basic notion of life-mind continuity (2016b).

\section{Responding to the Critics}

In this section, I respond to critics of AE's phenomenological heritage. I argue that the explicit concerns raised about phenomenology miss their mark, while those enactivist authors who have implicitly turned away from phenomenology are at odds with phenomenologically oriented enactivists on core theoretical issues that motivated the enactivist movement to begin with.

\section{De Jesus}

We begin with De Jesus' explicit concerns about enactivism's phenomenological heritage. First, it must be stressed that even if de Jesus is correct to identify these concerns in the Jonasian heritage of AE, this does not exhaust the phenomenological heritage of the movement. As Villalobos and Ward (2016, $806 \mathrm{n} 2$ ) point out, Jonas should not be taken as representative of phenomenology as such. De Jesus grants as much (2016a, 272n10), but then nonetheless goes on to argue that the points he raises against Jonasian phenomenology should be taken as grounds for enactivists to part with phenomenology altogether (286f.). As for de Jesus' more concrete objections, familiarity with classical and more recent phenomenology reveals them to be largely misguided.

Concerning (1), de Jesus claims that AE proponents, following Jonas, are guilty of taking epistemic (i.e., regulative) principles of inquiry and ascribing them ontologically (i.e., constitutively) (2016a, 277f.). For example, Weber and Varela (2002) assert that there is an immanent teleology characterizing the behavior of living beings: organisms are "subjects having purposes according to values encountered in the making of their living" (102). De Jesus' line of critique here goes back to Kant (2001), who 
acknowledged that, for the purposes of inquiry, we must treat organisms as though they operated teleologically, but that it does not necessarily follow that this category actually characterizes the organism in itself, ontologically speaking. It may just be that the organism appears to us to behave teleologically, and that describing it so is convenient for us methodologically. But that could be a function of our way of cognizing and investigating rather than a characteristic of the organism itself.

I think the phenomenologist's response to this critique is to question, and perhaps even reject outright, the stark contrast between regulative, merely epistemic principles that guide inquiry, and a deeper, ontological kind of principle that characterizes the being of $x$ in some supposedly more profound way. This distinction in Kant emerges from an architectonic view of human cognition and a corresponding conception of nature and experience that phenomenologists reject. Kant maintained that experience is structured by categories of the understanding derived from classical logic and forms of intuition corresponding to the spatiotemporal world of Euclidean geometry and classical mechanics. Within these limits, the categories of the understanding can be applied constitutively to yield objective knowledge of nature. Any pursuit of knowledge that goes beyond this narrowly circumscribed domain of experience, however, must employ merely regulative principles. But the limitations on knowledge and experience that Kant laid down have been transgressed within both the sciences and phenomenology. Phenomenologists maintain that there is much more to our experience of the lifeworld than can be accounted for given Kant's basic categories and forms of experience. It follows from Kant's transcendental deduction of the categories of the understanding that experience or knowledge of teleology can only be merely regulative. But phenomenologists need not accept these aprioristic conclusions concerning the nature and limits of understanding.

One basic feature of experience neglected in Kant's account is our experience of other agents. This brings us to (2) de Jesus' concerns about the phenomenological (or, more accurately, Jonasian) approach to other minds. According to Jonas, "life can only be known by life" $(1966,91)$. Picking up this line of reasoning, contemporary enactivists argue that it is through "our own evidence" (Weber and Varela 2002, 110) that we come to know the teleology that characterizes a living being. De Jesus (2016a, 278ff.) takes this as evidence that Jonas (and, by extension, AE advocates) is employing a sort of argument from analogy the likes of which have classically been invoked to address the problem of other human minds: seeing a likeness between the exterior behaviors of other human beings and myself, I am justified in inferring, by analogy, that they have a similar sort of interior experience and mentality corresponding to their outward behavior. However, since there are numerous difficulties with arguments from analogy (a point that is generally accepted and that I will not discuss at greater length here), $\mathrm{AE}$ premises its understanding of other minds on unstable ground by relying on Jonas' analogical inference.

I will not assess whether the most charitable way of interpreting Jonas' dictum that "life can only be known by life" is in terms of an analogical, inferential approach to other minds. I will simply point out that, drawing on the phenomenological tradition, $\mathrm{AE}$ has much broader resources for describing our access to other minds than the analogical approach. Indeed, de Jesus acknowledges as much, referring to contemporary phenomenological authors who begin their phenomenological accounts of empathy with a critique of the analogical approach to understanding other minds. The general point of such discussions is usually that, prior to any inferential or analogical procedure, we have an immediate, perceptual experience of another body as an animate being. I do not infer based on the external evidence of a body that it must possess a mind like my own "on the inside," as it were. Rather, I immediately experience the other animal body as minded. If de Jesus' critique of Jonas is in fact on 
point, and $\mathrm{AE}$ does indeed follow Jonas in this regard, the conclusion to draw might just as well be that AE should seek out better phenomenology rather than doing away with phenomenology altogether. ${ }^{5}$

In stating that our primary mode of access to other minds is perceptual and direct rather than inferential and indirect, phenomenologists can still leave room for analogical and theoretical reasoning about other minds. It may be the case that in making ascriptions of sentience or animacy, we increasingly rely on the analogical and reflective approach when the modes of behavior and embodiment of the body in question differ dramatically from our own. Thus, my uncertainty about whether, say, a robot, or a bacterium, is sentient may motivate recourse to analogical reasoning. Such reasoning may take into account not only the global activity of the organism or artifact in question but may also examine the subpersonal mechanisms underlying its activity. This more reflective reasoning system provides a valuable check on the initial perceptually-based ascription process, which is by no means an infallible guide to detecting agency and sentience (Barrett 2004). Analogical reasoning thus has a role to play in enactive and phenomenological discussions of the life-mind continuity thesis, especially the distinctively phenomenological version of the thesis advocated by $\mathrm{AE}$. It is here that $\mathrm{AE}$ might genuinely be exposed to de Jesus' critique. I will have more to say on this point below.

This brings us to (3), de Jesus' allegations of anthropomorphic tendencies in the phenomenological approach to understanding non-human minds. ${ }^{6}$ Because Jonas' analogical approach involves beginning with my distinctively human, phenomenologically described experience and using this as the basis for understanding the experience of a non-human organism, there is a risk of an "anthropomorphic projection" $(2016 a, 283)$ that violently imposes human structures onto the experience and mentality of non-human organisms.

Now, since, as we have seen, phenomenology is not bound to Jonas' analogical approach to other minds, it is not clear that the concern about anthropomorphism entailed by the analogical approach arises for alternative phenomenological approaches. Further, however, even if there is an anthropomorphic leaning in a fully developed phenomenological account of our access to other minds, it is not immediately obvious that all forms of anthropomorphism are pernicious in the study of nonhuman life and mind. It may well be that there is a salutary anthropomorphism without which it would be impossible to understand the experience of living things - though perhaps this is as much or more a theriomorphism than an anthropomorphism, relying on the fact of our shared animal (therion) form (morphé) of life rather than a specifically human one. Frans de Waal, one of the leading ethologists of our time, urges the need for a "critical anthropomorphism," writing that "anthropomorphism is not always as problematic as people think. To rail against it for the sake of scientific objectivity often hides a pre-Darwinian mindset, one uncomfortable with the notion of humans as animals" (de Waal 2016, 26). Merleau-Ponty had already seen the need for an "indispensable anthropomorphism" in discussing Köhler's breakthrough work with chimpanzees: "we must be subjective, since subjectivity is in the situation; but this is not to say that we should be arbitrary" (Merleau-Ponty 2010, 6; cf. Merleau-Ponty 1963, 161).

\footnotetext{
${ }^{5}$ See Gallagher and Zahavi $(2012,201 \mathrm{ff}$.) for a historical and contemporary introduction to the phenomenological approach to understanding other minds. Of course, the general validity and specific details of the phenomenological view on other minds are debated by authors working both within and without the phenomenological tradition. See, e.g., Overgaard (2017a, 2017b).

${ }^{6}$ De Jesus 2016a, 280ff. De Jesus distinguishes between anthropomorphism, anthropocentricism, and an anthropogenic approach, but for present purposes it will suffice to focus on the issue of anthropomorphism, which I take to be the central concern here.
} 
The point for now, pending further discussion, is that anthropomorphism comes in many flavors, and it may turn out that some are not only inescapable but even desirable for a phenomenology and science of life and mind. ${ }^{7}$ Whether phenomenology has any contribution to make to our understanding of nonsentient minds, by contrast, seems much more controversial. I will return to this point below.

\section{Radical Enactivism}

Let us now turn to REC's critique of AE's account of sense-making. REC, as we have seen, would reserve terms such as "sense-making" and "content-involving cognition" for socially-scaffolded, symbol-using minds. Basic minds, by contrast, are capable of a kind of intentional directedness, and perhaps even phenomenality, but their achievements do not warrant the title "sense-making." Hutto and Myin worry that the ascription of sense-making to basic minds by some AE authors could be evidence of a lingering representationalism.

In reading this line of critique, anyone familiar with the phenomenological tradition will suspect that Hutto and Myin have failed to grasp the level of description at which AE's notion of "sense-making" is meant to apply. Within phenomenology, there is a way of thinking about "meaning" (or "sense"), and even "content," that is logically and phenomenologically prior to the sort of representational (i.e., semantic or propositional) content that Hutto and Myin would like to eradicate from basic minds. As Claude Romano has noted, using the terms "meaning" and "signification" in a sense broader than the merely propositional sense could well serve as the hallmark of phenomenologists among analytic philosophers $(2015,66)$. For the phenomenologist, "sense" is not only, and not primarily, propositionally structured. Rather, things, experiences, and the world are meaningful. They make sense, and we make sense of them. The nature and structure of such "content" must be described independently and prior to that of propositional meaning. Though lengthy phenomenological treatises have been written on this topic, I will attempt over the balance of this paper to elucidate this level of phenomenological description and explain its importance for enactivism. ${ }^{8}$

Disregarding considerable variation among phenomenological authors, one can begin to characterize generally such a notion of basic "content" or meaning by stating that it is presentational rather than representational. Drummond provides a concise statement of such a view:

[O] ur mental events or states have intentional content by virtue of the intrinsic and fundamental intentionality of the mental event or state; they have intentional content by virtue of being directed upon worldly entities [...] and apprehending them in their significance. Entities - not

\footnotetext{
${ }^{7}$ Thompson has argued that the ability of two living bodies to resonate with one another - empathy broadly construed, in the phenomenological sense - is a precondition of any science of life and mind rather than being a threat to such science (MiL 165; Thompson 2005). It could well be argued that it is phenomenology alone, with its attention to the way in which the minds of other organism are initially given to us through their embodied activity, that can assess the nature and validity of the kinds of scientific evidence upon which a theory of non-human mindedness can be based. As Thompson also points out, a crucial task for a phenomenological cognitive science is to critique the false consciousness of the sciences of life and mind in their temptation towards a naïve objectivism (Thompson 2011, 118).

${ }^{8}$ For an excellent recent discussion of pre-predicative sense with respect to predicative and propositional sense, see Inkpin (2016).
} 
simpliciter but in their significance for us - are the intentional contents of mental events and states. (Drummond 2012, 123)

It should be clear that this notion of "content" is positioned at a level of description below the level at which REC's concerns about content are directed. If anything, the content in question here would be the (non-semantic, non-representational) content of basic minds themselves. Further, note that on this account the content of presentational states is intrinsically relational, not reducible to entities given under some supposedly subject-independent description. Rather, it is only in their significance for us that entities are presented to us. Objects of presentation are given in a particular way - with an asstructure, in the phenomenological idiom - and the way in which they are given depends on the subject to whom they are given. ${ }^{9}$

Now, up to this point, the defender of REC might maintain that the disagreement is merely verbal. After all, in their account of perception, Hutto and Myin happily grant that there is a certain aspectual character to perception that depends on the perceiver's perceptual capacities, motivations, and history of environmental engagements, among other things (RE 21,121). Perhaps, then, if all one means by presentational "meaning" or "content" is a certain aspectuality in the directedness of basic minds, the supposed disagreement here is more terminological than substantive (cf. RE 78).

I believe the disagreement is in fact substantive, and for two interrelated reasons. First of all, in fleshing out the details of a "basic mind" that interacts aspectually, dynamically, and creatively with its environment, phenomenologists have found that we end up describing a mind that is not so "basic" after all. This holds true not only for human perception and action, but - on Merleau-Ponty's view, at least - also for the perception and action of at least some higher animals. Hence more phenomenologically-inclined enactivists have had their doubts as to whether REC's basic minds can measure up to the creativity and flexibility of animal behavior (e.g., Kiverstein and Rietveld 2015). I will elaborate on this point below, when I attempt to articulate a robust notion of animal sense-making that requires a phenomenological, "content"-involving level of description but that is situated well below REC's scaffolded, symbol-using mind.

The more general point here, however, is that many phenomenologists classical and contemporary have their doubts about whether conventional scientific naturalism has the explanatory resources to account for this relational, phenomenological notion of sense-making. And this concern directs us to what I take to be the deeper substantive disagreement between Hutto and Myin, and Thompson: a disagreement about naturalism and phenomenology, and the relation between the two in enactivism more generally, including any possible priority claim for one over the other.

REC, as we have seen, is committed to explanatory naturalism. Much of the motivation for REC's radicalization agenda (and a central assumption of Hutto and Myin's master argument, the "hard

\footnotetext{
${ }^{9}$ In his review of Hutto and Myin's Evolving Enactivism (2017), Thompson (2018) also draws attention to Hutto and Myin's neglect of this level of phenomenological description. Thompson states that, while Hutto and Myin acknowledge an object-oriented mode of basic intentionality, they fail to discuss the mode of presentation that characterizes such intentionality. In their defense, Hutto and Myin do grant (1) that perception is aspectual (RE $113 \mathrm{ff}$. - see below), (2) that environmental offerings are given with a certain significance for the organism (RE 8), and (3) that there may be a kind of phenomenal content that is not necessarily representational content (EE 11). However, these topics are not developed in Hutto and Myin's work sufficiently to satisfy phenomenologicallyminded enactivists.
} 
problem of content") is that a rigorously naturalistic enactivism is preferable to alternative enactivist theories and non-enactivist, content-involving approaches in the cognitive sciences. Curiously, however, in pushing enactivism in this rigidly naturalistic direction, Hutto and Myin nowhere acknowledge that for many other enactivists, naturalism can by no means be taken for granted. And while most phenomenologically inclined thinkers associated with contemporary enactivism would accept some form of naturalized phenomenology (MiL 356ff.; Gallagher 1997, forthcoming; Zahavi 2017), this by no means entails that they would accept that phenomenology can be reduced to the natural sciences, nor that the natural sciences and their conception of nature are left untransformed after their mutual exchange with phenomenology. Thompson is explicit on this point, rejecting conventional naturalism with a transcendental-phenomenological argument drawn from Merleau-Ponty (MiL 81ff.; cf. 164f.). Far from being radical, on this issue REC has much more in common with conventional naturalistic approaches to the mind than it does with phenomenological enactivism.

Here is Thompson's summary of Merleau-Ponty's argument from The Structure of Behavior against the naturalism of early $20^{\text {th }}$ century behaviorism:

[N]aturalism needs the notion of form (and has come to recognize this need through its own inner development), but this notion is irreducibly phenomenal. Hence naturalism cannot explain matter, life, and mind, as long as explanation means purging nature of subjectivity and then trying to reconstitute subjectivity out of nature thus purged. (MiL, 81)

As stated here, the argument focuses on the notion of form, or structure, which is central to MerleauPonty's Gestaltist account of behavior and, ultimately, of nature itself. But this line of reasoning can easily be modified and wielded against REC. Consider REC's attempt to render the Gibsonian notion of affordance consistent with the kind of contentless cognition endorsed by REC (EE 92ff.). Like that of form, the notion of affordance is "irreducibly phenomenal." It is borrowed from phenomenal experience and makes sense only insofar as we locate it in phenomenal experience. It is also intrinsically relational, denoting an internal relationship between a subject and its world (cf. Gallagher forthcoming). REC's strategy of cashing out affordances in terms of the naturalist, external relation of informational covariation does not illuminate or explain the phenomenon in question, but rather obliterates it. The very terms in which REC attempts to conceive affordances would preclude the possibility of the phenomenon in question.

The specific case of affordances directs us towards a more general line of critique against REC's naturalism. Phenomenologically-oriented enactivists can object that REC's naturalism is either false or vacuous. This is a variation of the dilemma that Hempel famously posed to physicalism (Hempel 1969). If the "naturalism" with which Hutto and Myin seek to render enactivism consistent refers to some contemporary state of natural science, then their naturalism is false, for no existing naturalistic theory appears to be adequate to account for the whole of observed natural phenomena, with mind and consciousness proving to be particularly resistant to explanation. If, opting for the other horn of the dilemma, Hutto and Myin's naturalism refers to some future natural science and concept of nature, then their commitment is empty, for we do not yet know what will be included within the ontology and methodological resources of such a science. If they seize the first horn (as they appear to do in insisting that covariance is the only naturalistically admissible notion of information), then Hutto and Myin owe more phenomenologically-inclined enactivists a response to phenomenological concerns about naturalism. If they seize the second horn, then their appeal to naturalism is mere rhetoric, and their 
efforts would be better spent helping fellow enactivists work towards a new conception of nature and natural science (cf. Gallagher forthcoming).

\section{Giving the Critics their Due}

In light of these considerations, then, the gap between naturalistic REC and phenomenological AE proves to be greater than Hutto and Myin have estimated. Hutto and Myin (RE 78) quote Thompson from Mind in Life, where he writes that autonomous systems "enact an environment inseparable from their own structure and actions" (MiL 59). They claim that, substantively, they are in agreement with Thompson, but complain that "it only breeds confusion to use terms like 'meaning' [...] to describe the cognitive antics of bacteria. We prefer the more austere talk of informationally sensitive responses to natural signs." But they are wrong in thinking that the agreement is substantive, and that AE's idiom can be translated without perversion into REC's more austere, naturalistic terminology. For there is an irreducibly phenomenological dimension to AE's concept of "sense-making" that is completely ignored in REC's discussions. Indeed, in the very sentence following the one quoted by Hutto and Myin as evidence of substantive agreement, Thompson specifies that he intends his comments about "enacting an environment" to be taken in a phenomenological sense (MiL 59).

In the following section, I will present reasons for thinking that this phenomenological level of description cannot be translated without loss into Hutto and Myin's reductionist idiom of "informationally sensitive responses to natural signs." First, however, we should consider the scope of ascriptions of sense-making in $A E$. For AE's liberal ascription of sense-making within the organic domain is in part responsible for inviting radical enactivists to disregard and even cast suspicion upon the phenomenological dimension of enactivism. As we saw above, Thompson, following Jonas, maintains that wherever there is an autopoietic organism - wherever there is metabolism - there is a minimal mode of cognition that needs to be understood using a decidedly phenomenological level of description. Jonas thus serves to bridge the gap between an autopoietic, natural scientific notion of cognition that applies to all living beings, and Merleau-Ponty's phenomenological notion of behavior that applies to sensorimotor, animal life.

The problem, however, with equating autopoietic (basic, metabolic) cognition with Merleau-Ponty's sensorimotor notion of behavior, as Thompson sometimes does (e.g., MiL 124ff.), is that the phenomenological terminology is now being used equivocally. Phenomenological description was designed paradigmatically to apply to the first-person experience of human agents, sentient beings for whom there is something it is like to be the being in question. We have warrant to extend such descriptions to the experience of beings other than ourselves insofar as we have good reason to believe that these beings also enjoy a first-personal, sentient experience, even if it is only minimal and prereflective. AE authors deny sentience to unicellular organisms (MiL 161f.), but nonetheless claim that their descriptions of the unicellular organism's "perspective" (MiL 154) or "point of view" (Colombetti $2014,15-20$ ) are meant in a phenomenological sense. But such ascriptions risk emptying the phenomenological notion of sense-making of its sense, obfuscating the proper explanatory work it should be doing within enactivism, and vindicating radicalists who either ignore or explicitly reject the phenomenological dimension of enactivism. 
It may be true, as Jonas and many $A E$ advocates maintain, that with the arrival of an autopoietic organism in the universe, a new level of scientific description beyond the physico-chemical is required. The activity of a unicellular organism is norm-involving: there is a better and a worse for such an organism. Correlatively, there may be something missing from a description of the surrounding environment of the unicellular organism that does not recognize that molecules in the physico-chemical environment have a vital significance for the survival of the organism (cf. MIL 154). But such leveling up in description does not yet necessarily entail the need for a specifically phenomenological level of description. To see why, consider an analogous case. Suppose that the chemical level of description of molecular interactions is irreducible to the merely physical level of description. (For the purposes of my argument, it makes no difference whether this is in fact the case.) The molecule is a unique kind of chemical unity and accounting for its activity demands a new set of scientific resources beyond those of physics. Would it follow from this that it is because of the "perspective" or "point of view" of the molecule upon its environment that this new level of description is required? And, even supposing that those working in the field agreed to such terminology, would it follow that it is continuous with phenomenological descriptions of sentient experience, such that the "inwardness" of the molecule can only be understood by employing a uniquely phenomenological idiom?

Of course, denying that there is a place for a phenomenological, first-personal sense of normativity or teleology in the activity of non-sentient organisms needn't entail that autopoietic enactivists are stuck with a merely teleonomic account of unicellular autonomy. There may be an "intrinsic teleology" of the living (Weber and Varela 2002) more ontologically robust than mere teleonomy that still falls short of the kind of meaning-making phenomenologists describe for sentient organisms. Aristotle, after all, maintained that teleology is pervasive in the natural world, but did so without assuming anything like a phenomenological level of description was required to understand the vital processes of plants. Like Aristotle, we should admit hierarchy into our continuity. How the teleology at play in more basic life processes relates to the teleology at play on the level of sentience is a crucial and challenging question for enactivists, as it was for Aristotle.

As Spahn has noted $(2016,83 f$.), there has been a tendency to conflate the views of Thompson, Jonas, and Merleau-Ponty on many of these issues. Disentangling their views can help us restore a MerleauPontian notion of sense-making that is indispensable for enactivism and irreducible to REC's naturalist notion, but that also does not apply as broadly in the organic domain as Thompson and Jonas claim. Here it is worth stressing once again that Merleau-Ponty's first book, The Structure of Behavior from 1942, concerns the behavior of animals with central nervous systems alone and contains no discussions of plants or unicellular organisms. A decade after the publication of The Structure of Behavior, in a lecture course on phenomenology and the human sciences, Merleau-Ponty explicitly warns against the position Jonas and Thompson would later take, stating that the attempt "to account for the behavior of unicellular beings with the aid of categories from human behavior" is an "error of biologists" (MerleauPonty 2010, 369). And he returns to the topic of behavior in his lectures on the concept of nature from the late 1950s. Here is Thompson's discussion of one of Merleau-Ponty's remarks from that course:

When Merleau-Ponty writes, in his lecture course on Nature (discussing von Uexküll), "the reactions of the animal in the milieu ... behaviors ... deposit a surplus of significance on the surfaces of objects," his description applies also to microbial life: the reactions of the bacteria in their milieu-their tumbling and directed swimming-deposit a surplus of significance on the surfaces of molecules. (Thompson 2011, 119; quoting Merleau-Ponty 2003, 172f.) 
Thompson's claim that Merleau-Ponty's description applies equally well to microbial life need not be taken as an exegetical remark. He may not mean to suggest that Merleau-Ponty shares his view that the description in question applies equally to microbial and animal life. Nonetheless, it should be stressed that in the broader context of the passage just quoted, Merleau-Ponty appears to be denying precisely the view that Thompson is endorsing. Merleau-Ponty's description is meant to characterize the form of life of higher animals as opposed to that of lower animals (and, by extension, microbial life). ${ }^{10}$ These texts are difficult to interpret. They are sketchy in many places, mere notes rather than fully developed views. Further, in the passage in question, it is not clear whether Merleau-Ponty is advancing a view he himself endorses or merely offering an exposition of von Uexküll's position. However, what MerleauPonty appears to be saying, consistent with his position in previous works, is that depositing a "surplus of significance on the surfaces of objects" - sense-making in a properly phenomenological sense - is unique to higher animals. With respect to the lower animals, the central nervous system of the higher animals is said to constitute an "absolute novelty, a neoformation [Neubildung]" (Merleau-Ponty 2003, 171). It is at this level of behavior, not that of basic metabolism, that we require phenomenological description. Sentience, or minimal, pre-reflective experience, is a necessary condition for the kind of sense-making that is of interest to phenomenologists and phenomenological enactivists. But this point has been lost with the generalized attribution of a phenomenologically inflected notion of sense-making to all metabolic organisms. To that extent, the critics are justified in claiming that the AE notion of sense-making is misleading or mistaken.

Of course, just how deep the phenomenological dimension of the life-mind continuity thesis runs remains an open and important question for enactivist thought. In the remainder of this paper, I will propose an alternative approach to this question to the one offered by AE up to this point.

\section{Exploring Continuity from the Top Down}

Up to this point, my ambition has been largely expository and clarificatory, establishing the lines of agreement and disagreement between radical and autopoietic enactivists, Merleau-Ponty and Jonas. My suggestion is that enactivists continue to explore the phenomenological dimensions of the life-mind continuity thesis, but that they do so following Merleau-Ponty rather than Jonas. Specifically, we should explore continuity from the top down, by beginning with those branchings of the phylogenetic tree that are closest to our own. In doing so, we can make a much more compelling case for a robust notion of sense-making that is entirely sub-symbolic (contra REC) but that truly demands a phenomenological level of description.

In the domain of animal psychology, today's phenomenologically oriented enactivists find themselves confronting radical enactivists in a way that recapitulates the position taken by Gestalt psychologists who opposed behaviorists a century ago. Merleau-Ponty was deeply influenced by the work of the Gestaltists in this domain, especially Köhler's work with chimpanzees (Köhler 1927), which MerleauPonty discusses at numerous places in the decade spanning The Structure of Behavior and his lectures at the Sorbonne in the early 1950 s. ${ }^{11}$ Chimpanzee problem solving, illustrated in cases of tool use discussed

\footnotetext{
${ }^{10}$ As examples of "lower animals," Merleau-Ponty discusses medusas, marine worms, starfish, and sea anemones. In a somewhat unusual classificatory move, Merleau-Ponty, following von Uexküll, includes amoebas and paramecia, both unicellular organisms, among "lower animals."

${ }^{11}$ Merleau-Ponty 1963, 112f.; 1964a; 1964b, 75; 1973, 104, 119f.; 2010, 6f., 151, 209-13, 345, 430.
} 
by Köhler and Merleau-Ponty, provides a paradigmatic illustration of the kind of sense-making activity that should be of interest to enactivists. Here is Köhler's description of the behavior of a chimpanzee tasked with obtaining a banana that is beyond its grasp through a grill:

After many failures, [Tschego] finally sits down quietly. But her eyes wander and soon fix on the little tree, which she had left lying a little way behind her, and all of a sudden, she seizes it quickly and surely, breaks off a branch, and immediately pulls the objective to her with it. (Köhler 1927)

Köhler stresses that we must distinguish qualitatively between Tschego's behavior and a solution achieved through chance or trial and error. In Tschego's case, the solution is preceded by Einsicht, or, in a more enactive idiom, by the recognition of a perceptual affordance in the situation that had not previously been disclosed.

In his discussions of the importance and consequence of this work, Merleau-Ponty maintains that Köhler, by highlighting the shortcomings of behaviorism's objectivist, third-person, reductionist approach to behavior, has shown that "in addition to our own perceptual universe, we have to reconstitute the animal's universe in all its originality" (Merleau-Ponty 1964a). To this end, he makes the following remark in a lecture course from 1951-52:

Chimpanzees are capable of conferring new meanings on objects which are not naturally connected with them (e.g., they use a stick to get bananas). The old and naturally established totality is destroyed in order to establish a new one. This operation merits the name of intelligence." (Merleau-Ponty 2010, 430 - emphasis added)

Here we have sense-making in a phenomenological sense of the word: the subject actively and creatively construes its perceived world in a new way so as to enable a qualitatively different mode of behavior. It is only by taking the situation differently, by conferring new meaning upon the perceived world, that Tschego is able to solve the problem posed by the branch on the other side of the grill. This is not only perceiving as (i.e., perceiving aspectually, an ability that REC happily ascribes to non-human perceivers), but rather perceiving otherwise. How does Merleau-Ponty's description compare with the kind of description that REC could provide of the same behavior?

Two points are in order here. First of all, recall that on the sub-symbolic level, REC's basic minds are capable only of informational covariance. A kind of "contentless," object-directed intentionality is possible here, one that allows organisms to "target chunks of the world" (EE 52). But note how different this way of describing the world of the organism is compared to Merleau-Ponty's Gestaltist description of the perceived world of the chimpanzee as a meaningful totality. As we saw above, a central claim of The Structure of Behavior is that behavior must be grasped in relational, situational terms that do not reduce to naturalistic, objectivist notions such as stimuli, "world chunks," or "informationally sensitive responses to natural signs" construed as covariation. Second, in Merleau-Ponty's and Köhler's descriptions, the chimpanzee fully warrants being called the meaning-maker in the behavior in question. Such an organism is not merely "set up to be set off by certain worldly offerings," as Hutto and Myin put it (RE 19), but rather changes its own "settings." It perceives as, but also, through its own active processes of sense-making, comes to perceive otherwise, conferring new meaning upon its perceptual and behavioral environment. And without attributing this kind of phenomenologically described sensemaking, the behavior is not intelligible to the scientific observer. 


\section{Conclusion}

In rehearsing and updating the lines of reasoning that Merleau-Ponty and Köhler addressed to the behaviorists of their time, I provide only the first adumbrations of the kind of phenomenological account of sense-making I think enactivists will need to account for the full gamut of human and animal experience and behavior. Choosing one's descriptive resources, with their attendant ontological and methodological commitments, is never a simple affair, and this case is no different. There is never an airtight argument in favor of one scientific paradigm over another. My primary objective has been to show that the choice between REC's naturalism and AE's phenomenology is not a "merely terminological" matter, but rather amounts to a crucial choice about the foundations of enactivism. I have attempted to provide the outline of a phenomenological account of sense-making that would tip the scales in favor of a modified AE account, restricting the attribution of sense-making to the class of sentient animals whose exact limit I have not attempted to define. And I will recall once again one of the initial motivations of enactivism, the reminder that a cognitive science that leaves out the experiential dimension of mind is missing half the story of the mind - and the more interesting half at that.

My proposal is that it is at the highest level of intelligent, non-symbolic behavior, and the description thereof, that we should initially seek to position the phenomenological dimension of enactivism and its characteristic notion of sense-making. This allows AE to escape between the horns of the dilemma presented by radical critiques that claim AE's notion of sense-making must be either empty or contaminated by representationalism. From here out, we can begin exploring the subjective and phenomenological aspects of the life-mind continuity thesis. In this light, it is surprising that autopoietic enactivists have had so much to say about unicellular "sense-making," and the sense-making activities of organisms in general and as such, but less to say about the specific experiential worlds and sensemaking of our closest kin, the higher animals. ${ }^{12}$ The approach I am advocating - call it phenomenological ethology - would remedy this lacuna and begin fleshing out the life-mind continuity thesis in much richer detail than the largely formal, theoretical picture of continuity that we have at present. The price to be paid for this finer granularity will likely be that we must acknowledge more discontinuities amid continuity than tend to be emphasized in current enactivist presentations of life-mind continuity. Like Aristotle, we should recognize both continuity as well as hierarchy and discontinuity. One such discontinuity, the sentient-vs-non-sentient divide, has been discussed in this paper. Another will likely be a discontinuity that arises with the pervasively cultural, social, and historical form of life that is unique to our species, a topic for generative phenomenology (cf. MiL, 33ff.). This new emphasis on discontinuity notwithstanding, my proposal is inspired by a deep admiration for the original enactivist project of uniting phenomenology with the sciences of life and mind, and the hopes that this endeavor will serve the broader philosophical-anthropological goal of deepening our understanding of our place human, animal, and organic - on the planet and within the cosmos.

\footnotetext{
${ }^{12}$ Kiverstein and Rietveld (2015) is a notable exception to this trend. Barandiaran (2017) and Barandiaran and Moreno $(2006,2008)$ also conclude that the animal level of sensorimotor autonomy is the one that is relevant to the $A E$ notion of behavior, but they arrive at this conclusion for reasons more scientific than phenomenological. Stapleton and Froese (2016) emphasize the importance of the nervous system, highlighting discontinuities in the life-mind continuity thesis where notions of subjectivity and agency are concerned. And, their strong commitment to continuity notwithstanding, both Thompson (MiL 47-49, 243ff.) and Jonas (1966, 99ff.; 1968, 244ff.) emphasize the uniqueness of the animal sensorimotor form of life.
} 


\section{Bibliography}

Barandiaran, Xabier E. 2017. "Autonomy and Enactivism: Towards a Theory of Sensorimotor Autonomous Agency." Topoi 36 (3): 409-30.

Barandiaran, Xabier E., and Alvaro Moreno. 2006. "On What Makes Certain Dynamical Systems Cognitive: A Minimally Cognitive Organization Program.” Adaptive Behavior 14 (2): 171-85. 2008. "Adaptivity: From Metabolism to Behavior." Adaptive Behavior 16 (5): 325-44.

Barrett, Justin L. 2004. Why Would Anyone Believe in God? Walnut Creek, CA: AltaMira Press.

Colombetti, Giovanna. 2014. The Feeling Body: Affective Science Meets the Enactive Mind. Cambridge, Mass.: MIT Press.

De Jesus, Paulo. 2016a. “Autopoietic Enactivism, Phenomenology and the Deep Continuity Between Life and Mind." Phenomenology and the Cognitive Sciences 15 (2): 265-289.

2016b. "From Enactive Phenomenology to Biosemiotic Enactivism." Adaptive Behavior 24 (2): 130-46.

Di Paolo, Ezequiel. 2005. "Autopoiesis, Adaptivity, Teleology, Agency.” Phenomenology and the Cognitive Sciences 4 (4): 429-52.

Drummond, John. 2012. "Intentionality Without Representationalism." In The Oxford Handbook of Contemporary Phenomenology, edited by Dan Zahavi, 115-33. Oxford: Oxford University Press.

Gallagher, Shaun. Forthcoming. "Rethinking Nature: Phenomenology and a Non-Reductionist Cognitive Science.” Australasian Philosophical Review.

1997. "Mutual Enlightenment: Recent Phenomenology in Cognitive Science.” Journal of Consciousness Studies 4 (3): 195-214.

Gallagher, Shaun, and Dan Zahavi. 2012. The Phenomenological Mind. London: Routledge.

Hempel, Carl. 1969. "Reduction: Ontological and Linguistic Facets." In Philosophy, Science, and Method: Essays in Honor of Ernest Nagel, edited by M. P. S. Suppes White Morgenbesser, 17999. New York: St Martin's Press.

Hutto, Daniel D., and Erik Myin. 2013. Radicalizing Enactivism: Basic Minds Without Content. Cambridge, Mass: The MIT Press.

- 2017. Evolving Enactivism: Basic Minds Meet Content. Cambridge, Massachusetts: The MIT Press.

Hutto, Daniel D., and Glenda Satne. 2015. "The Natural Origins of Content.” Philosophia 43 (3): 521536.

Inkpin, Andrew. 2016. Disclosing the World: On the Phenomenology of Language. Cambridge, Mass: The MIT Press.

Jonas, Hans. 1966. The Phenomenon of Life: Toward a Philosophical Biology. Chicago: University of Chicago Press.

1968. "Biological Foundations of Individuality." International Philosophical Quarterly 8 (2): 231-251.

Kant, Immanuel. 2001. Critique of the Power of Judgment. Translated by Paul Guyer and Eric Matthews. Cambridge: Cambridge University Press.

Kiverstein, Julian, and Erik Rietveld. 2015. "The Primacy of Skilled Intentionality: On Hutto \& Satne's the Natural Origins of Content." Philosophia 43 (3): 701-21.

Köhler, Wolfgang. 1927. The Mentality of Apes. Translated by Ella Winter. London: Routledge and Kegan Paul.

Maturana, Humberto. 1980. "Biology of Cognition." In Autopoiesis and Cognition: The Realization of the Living, 2-58. Boston Studies in the Philosophy of Science 43. Dordrecht: D. Reidel. 
Maturana, Humberto, and Francisco J. Varela. 1980. Autopoiesis and Cognition - The Realization of the Living. Boston Studies in the Philosophy of Science 42. Dordrecht: D. Reidel.

Merleau-Ponty, Maurice. 1963. The Structure of Behavior. Translated by Alden L. Fisher. Boston: Beacon Press.

1964a. "The Metaphysical in Man.” In Sense and Non-Sense, translated by Hubert L. Dreyfus and Patricia Allen Dreyfus, 83-98. Evanston: Northwestern University Press. 1964b. The Primacy of Perception: And Other Essays on Phenomenological Psychology, the Philosophy of Art, History, and Politics. Edited by James M. Edie. Evanston: Northwestern University Press.

1973. The Prose of the World. Translated by John O’Neil. Evanston: Northwestern University Press.

2003. Nature: Course Notes from the Collège de France. Edited by Dominique Seglard.

Translated by Robert Vallier. Evanston: Northwestern University Press.

2010. Child Psychology and Pedagogy: The Sorbonne Lectures 1949-1952. Translated by Talia Welsh. Evanston: Northwestern University Press.

Overgaard, Søren. 2017a. "Merleau-Ponty and Wittgenstein on Mindreading: Exposing the Myth of the Given Mind." In Wittgenstein and Merleau-Ponty, edited by Komarine Romdenh-Romluc, 49-65. New York: Routledge.

- 2017b. "Other Minds Embodied." Continental Philosophy Review 50 (1): 65-80.

Romano, Claude. 2015. At the Heart of Reason. Edited by Anthony J. Steinbock. Translated by Michael B. Smith. Evanston: Northwestern University Press.

Sheredos, Benjamin. 2017. "Merleau-Ponty's Immanent Critique of Gestalt Theory." Human Studies 40 (2): 191-215.

Spahn, Christian. 2016. "Beyond Dualism? The Implications of Evolutionary Theory for an Anthropological Determination of Human Being." In Embodiment in Evolution and Culture, edited by Gregor Etzelmuller and Christian Tewes, 73-96. Tübingen: Mohr Siebeck.

Stapleton, Mog, and Tom Froese. 2016. "The Enactive Philosophy of Embodiment: From Biological Foundations of Agency to the Phenomenology of Subjectivity." In Biology and Subjectivity, 11329. Historical-Analytical Studies on Nature, Mind and Action. Cham: Springer.

Thompson, Evan. 2005. "Empathy and Human Experience." In Science, Religion, and the Human Experience, edited by James D. Proctor. Oxford: Oxford University Press.

2007. Mind in Life: Biology, Phenomenology, and the Sciences of Mind. Cambridge, Mass: Harvard University Press.

. 2011. "Living Ways of Sense Making." Philosophy Today 55 (Supplement): 114-123.

. 2018. Review of Review of Evolving Enactivism: Basic Minds Meet Content, by Erik Myin and

Daniel D. Hutto, January. https://ndpr.nd.edu/news/evolving-enactivism-basic-minds-meetcontent/.

Thompson, Evan, and Mog Stapleton. 2009. "Making Sense of Sense-Making: Reflections on Enactive and Extended Mind Theories." Topoi 28: 23-30.

Varela, Francisco J. 2000. El Fénomena de La Vida. Santiago: Dolmen Essayo.

Varela, Francisco J., Evan Thompson, and Eleanor Rosch. 1991/2016. The Embodied Mind: Cognitive Science and Human Experience. Revised second edition. Cambridge, MA: The MIT Press.

Villalobos, Mario, and Dave Ward. 2016. "Lived Experience and Cognitive Science: Reappraising Enactivism's Jonasian Turn.” Constructivist Foundations 11 (2): 204-12.

Waal, Frans de. 2016. Are We Smart Enough to Know How Smart Animals Are? New York: W. W. Norton \& Company.

Weber, Andreas, and Francisco J. Varela. 2002. "Life after Kant: Natural Purposes and the Autopoietic Foundations of Biological Individuality." Phenomenology and the Cognitive Sciences 1 (2): 97 125.

Zahavi, Dan. 2017. Husserl's Legacy: Phenomenology, Metaphysics, and Transcendental Philosophy. Oxford: Oxford University Press. 